Tropical Journal of Pharmaceutical Research July 2014; 13 (7): 1169-1177

ISSN: $1596-5996$ (print); 1596-9827 (electronic)

(C) Pharmacotherapy Group, Faculty of Pharmacy, University of Benin, Benin City, 300001 Nigeria.

All rights reserved.

Available online at http://www.tjpr.org

Review Article

http://dx.doi.org/10.4314/tjpr.v13i7.23

\title{
Gold Nanoparticles: Synthesis and Applications in Drug Delivery
}

\author{
AK Khan ${ }^{1}$, R Rashid ${ }^{1}$, G Murtaza ${ }^{2 *}$ and A Zahra ${ }^{1}$ \\ ${ }^{1}$ Department of Chemistry, ${ }^{2}$ Department of Pharmacy, COMSATS Institute of Information Technology, 22060 Abbottabad, \\ Pakistan \\ *For correspondence: Email: gmdogar356@gmail.com; Tel: +92-314-2082826; Fax: +92-992-383441
}

Revised accepted: 2 June 2014

\begin{abstract}
This review is focused essentially on the synthesis and applications of gold nanoparticles in the field of medicine and targeted drug delivery. Nanotechnology has become one of the most interesting and advanced areas of research in this field. Among nanoparticles, gold nanoparticles demonstrate special advantages in this field due to their unique properties, small size and high surface area-to-volume ratio. These particles have been widely used in various biomedical applications and drug delivery systems due to their inert nature, stability, high dispersity, non-cytotoxicity and biocompatibility.
\end{abstract}

Keywords: Biosynthesis, Gold nanoparticles, Biomedical applications, Targeted drug delivery, Nanotechnology.

Tropical Journal of Pharmaceutical Research is indexed by Science Citation Index (SciSearch), Scopus, International Pharmaceutical Abstract, Chemical Abstracts, Embase, Index Copernicus, EBSCO, African Index Medicus, JournalSeek, Journal Citation Reports/Science Edition, Directory of Open Access Journals (DOAJ), African Journal Online, Bioline International, Open-J-Gate and Pharmacy Abstracts

\section{INTRODUCTION}

The term "nano" is derived from the Greek word "nanos" which means small and it is used as the prefix for one billionth part $\left(10^{-9}\right)$. According to American Society for Testing and Materials (ASTM international 2006), nanoparticles are those particles which have two or more than two dimensions and are in the size range of $1-100$ $\mathrm{nm}$ [1]. These particles have special and enhanced physical and chemical properties as compared to their bulk materials due to their large reactive and exposed surface area and quantum size effect as a result of specific electronic structures. These particles have been widely used in many fields such as electronics, photochemical, biomedicine and chemistry [2].

Inorganic nanoparticles and combination of inorganic nanoparticles with organic materials to form hybrids possess unique physical, chemical, optical and electrical properties which make them different and more applicable than large size materials. Nanoparticles are proved to be promising multi-functional platform because they can be used for many imaging and therapeutic functions. These types of platforms can be synthesized by different organic, inorganic or hybrid of organic and inorganic materials but among all these inorganic platforms are of most important for diagnosis and simultaneous therapy due to their easy modification, stability and high drug loading capacity [3].

Recently much attention has been paid towards controlling the shape and size of metal nanostructures because all the magnetic, catalytic, electrical and optical properties of metal nanostructures are influenced by their shape and size. Nanoparticles have wide applications in the field of biomedicine such as to deliver pharmaceutics, for diagnostic approaches as well 
as for the therapeutic purposes because nanoparticles have very small sized particles, they can be used for targeted drug delivery and the metallic nanoparticles respond resonantly to the magnetic field which varies with time so they transfer enough toxic thermal energy to the tumor cells as hyperthermic agents [4]. Metal nanoparticles specifically gold nanoparticles have abundant use in the field of biotechnology and biomedicine because they have large surface bio conjugation with molecular probes and they also have many optical properties which are mainly concerned with localized plasmon resonance $(\mathrm{PR})[5]$.

Nanoparticles cover a broad area of interest including electronics, medicine, food industry, environmental applications and cosmetics. Furthermore due to the metallic properties these metal nanoparticles exhibit photoelectric effect which neutralizes the photo bleaching concerns related with the conventional fluorescent dyes. Surface modification of the nanomaterials have strong effect on the interaction of these nanomaterials with cells, in addition to this it also helps to convert toxic nanomaterials to the less toxic or less toxic to more toxic nanomaterials [6]. Nanoparticles have been used to enhance the selectivity and efficiency of the drug delivery system because they act as mediators of drug release. Nanoparticles have extremely small size and high surface area hence their surfaces has been available for further modification with hydrophobic, hydrophilic, cationic, anionic or any neutral moieties to the surrounding environment so they have many application in biological sciences.

Drug delivery systems based on nanoparticles have proved to be a great route for targeting malignant brain tumors where the conventional therapy is not as much effective. Enhanced permeability and retention (EPR) is the unique property of nanoparticles to accumulate and interact with the tumor cells [7]. Platelets plays a vital role in the development of cardiovascular diseases so the antiplatelet agents are considered as the necessary components for the curing such diseases. Therefore, the interaction of nanoparticles and the vascular pathway becomes an essential part of the management and prevention of cardiovascular disease. Among all metallic nanoparticles the gold nanoparticles proved to be the safest and much less toxic agents for drug delivery and for hyperthermic agents for the cancer treatment [8]. Nanotechnology induced advance approaches in the field of biomedical sciences specially related to the cancer therapy and for diagnostic applications regarding efficient drug delivery and reduced side effects as compared to the conventional drugs, which have been used for cancer treatment. Main properties of nanoparticles to be an effective drug delivery agent includes monodispersity, lack of cytotoxicity and simple mechanism of interaction with desired ligands. One the basis of these characteristics many nanoparticles have been synthesized and used in cancer treatment, drug delivery systems and imaging such as dendrimers, quantum dots, polymer gels, gold nanoparticles, $\mathrm{ZnO}$, or $\mathrm{Fe}_{2} \mathrm{O}_{3}$ [9]. Various chemical and physical methods have been adapted for the synthesis of nanoparticles which are quite expensive and the chemicals used are harmful to the environment. To overcome these problems green synthesis is emerging field of research of current era. Inorganic nanoparticles have particular application in molecular imaging as contrast agent such as magnetic resonance imaging (MRI), positron emission tomography (PET), computed tomography (CT), ultrasound and optical imaging [10]. This review focuses gold nanoparticles as important area of research regarding biomedical applications especially in cancer therapy.

\section{GOLD NANOPARTICLES}

Properties of gold nanoparticles are different from its bulk form because bulk gold is yellow solid and it is inert in nature while gold nanoparticles are wine red solution and are reported to be anti-oxidant. Inter particle interactions and assembly of gold nanoparticles networks play key role in the determination of properties of these nanoparticles [11]. Gold nanoparticles exhibit various sizes ranging from $1 \mathrm{~nm}$ to $8 \mu \mathrm{m}$ and they also exhibit different shapes such as spherical, sub-octahedral, octahedral, decahedral, icosahedral multiple twined, multiple twined, irregular shape, tetrahedral, nanotriangles, nanoprisms, hexagonal platelets and nanorods (Figure 1).

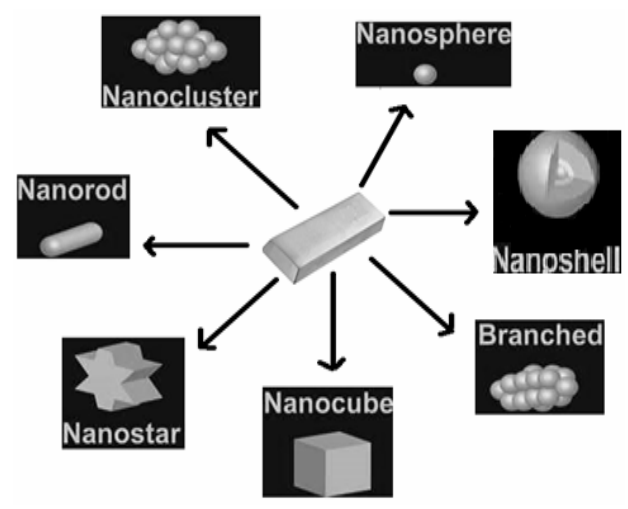

Figure 1: Various shapes of gold nanoparticles 
Among all these shapes triangular shaped nanoparticles show attractive optical properties as compared to the spherical shaped nanoparticles. Using of single active substance from plant extract in the synthesis of gold nanoparticles is an important bio synthesis technique to purify gold nanoparticles and to investigate about their medical uses. Gold nanoparticles have been widely used in the field of radiation medicine as radiation enhancer [12] and also provide therapeutic enhancement in radiation therapy due to the efficient and targeted drug delivery to the tumor site. Gold nanoparticles have various applications as platform nanomaterials for biomolecular ultrasensitive detection, killing cancer cells by hyperthermal treatment, labeling for cells and proteins and delivering therapeutic agents within cells.

Fluorescent nanoparticles or nanoprobes based on gold nanoparticles have good biocompatibility for molecular imaging of many enzymes and metabolites which is necessary for cellular functions in cancer. Gold nanorods have gained much attention in recently few past years due to their specific optical and chemical property and hence used for biological applications [13]. Gold nanorods have unique anisotropic geometry which enables them to get tunable absorption in both visible and near infrared (NIR) regions and make them suitable for potential applications in the fields of biosensing, gene delivery and photo thermal therapy. Gold nanoparticles have various advantages over conventional iodine-based agents as gold has higher absorption coefficient than iodine due to its higher atomic number and electron density so it enhance CT contrast more than iodine so they have been used in X-ray CT imaging as molecular probes [14].

The second major advantage of gold nanoparticles is that they are non-cytotoxic and third most important benefit is regarding their surfaces, as they have large surface area due to which their surfaces are readily available for modification with targeting molecules or specific biomarkers and applicable in biomedical purposes [15]. The role of gold nanoparticles in biological sciences is very important because of the compatibility, conjugation of these particles to the biomolecules and their tunable optical properties which are due to the shape, size and surface area of the gold nanoparticles. Due to the small size and large surface, shape and crystallinity, nanoparticles are proved to be excellent therapeutic agents because they can easily travel into the target cells and can bear high drug load [16].
Gold nanoparticles are widely used in biomedical science including tissue or tumor imaging, drug delivery, photo thermal therapy and immunochromatographic identification of pathogens in clinical specimens due to the surface plasmon resonance (SPR) [17]. Nanoparticles have unique physiochemical properties including surface area, amphilicity, shape, biocompatibilities and surface carrier capabilities which make them suitable for gene delivery, as the function of conjugated gold nanoparticles described by various factors such as protein structure, particle morphology and conjugated strategy [18]. Gold nanorods have various applications in the field of in vivo imaging due to the plasmon resonance absorption and scattering of light in the near infrared region [19]. Colloidal gold nanoparticles have also gain much attention due to their easy preparation through chemical methods and they can easily be imported to the tissues and cells because of their very small size which is equal to the biological molecules like DNA and proteins [20].

Gold nanoparticles can bind with a wide range of organic molecules as they have low toxicity and tunable physical and chemical properties so they have been used as therapeutic agents or vaccine carriers in to the specific cells so that they can increase the efficiency of drugs and can destroy pathogens. By using gene gun gold nanoparticles have been extensively used for epidermal delivery of DNA vaccines and this method is one of the best methods to deliver DNA vaccine. Coated walls of gold nanocages with temperature-sensitive polymer were used as drug carrier which releases their effectors with interaction of near-infrared irradiations [21]. Gold nanoparticles having small size and diameter about $1 \mathrm{~nm}$ are able to cross the cell membrane and nucleus to interact with DNA on the contrary gold nanoparticles of size $18 \mathrm{~nm}$ exhibit excellent penetration in to cells but cytotoxicity was not observed [22].

Gold nanoparticles have strong affinity for alkynes as compared to other transition metal catalysts but the homogeneous systems are not favorable economically and environmentally because of rapid reduction of active gold complexes in to inert metallic gold during the $\mathrm{C}-\mathrm{H}$ alkyne activation. Due to the unique optical and electronic properties of gold nanoparticles they have been widely used in the color indicating probes in the development of analytical techniques which are used for the sensing of various analytes [23]. Gold colloids have been used in the surface modification of ideal electrodes due to their remarkable stability and unique properties including high biocompatibility 
which is necessary to retain the native structure and enzymatic activity of attached proteins or enzymes. Combination of gold nanoparticles into smart polymer like poly ( $\mathrm{N}$-isopropylacrylamine) is an effective process to enhance the various properties of polymer such as showing swell of collapse reversibility in response to the temperature stimuli [24].

\section{SYNTHESIS STRATEGIES}

Various methods have been developed for the synthesis of gold nanoparticles and these methods follows the same rules as the preparation methods of other particles [25]. General methods for the synthesis of gold nanoparticles include chemical, physical, and biological methods which are explained below.

\section{Chemical methods}

Gimenez et al proposed a method to synthesize gold nanoparticles supported on an insoluble thiolated chitosan derivative by reduction of the $\mathrm{HAuCl}_{4}$ through thiolated chitosan (QTDT) as reducing and coupling agent for gold nanoparticles so the synthesized QT/Aunano is used as a good catalyst for the reduction of methylene blue [26]. Citrate thermo reduction method was used for the synthesis of gold nanoparticles having efficient SERS (surface enhanced Raman spectroscopy) in short reaction time by using a low cost reagent inositol hexaphosphate (IP6) as reduction agent for $\mathrm{HAuCl}_{4}$ [27]. Another method used for the synthesis of thermo-sensitive gold nanoparticles was reported. In this method gold nanoparticles was reduced by the trisodium citrate which was combined with hydrogen tetrachloroaurate (III) tetrahydrate (chloroauric acid) and modified with 11-mercaptoundecanoic acid (MUA) by the selfassembly monolayers (SAM) [6].

The synthesis of gold nanoparticles via seeding growth method has also been reported. Gold nanoparticles were grown from gold nanoparticles encapsulated in polyethylene glycol attached with dendrimers and have high near infra-red absorption by using formaldehyde as a reducing agent [28]. Gold nanoparticles of size range 1.8 - $3.7 \mathrm{~nm}$ have been synthesized by using peptide-biphenyl hybrids (PBHs) which are good stabilizer for gold as capping agents via single-phase system. Size of gold nanoparticles synthesized depends upon the structure and type of capping agent being used [17]. The reduction method has been used for the preparation of dendrimers/Au nanoparticles. These particles were synthesized by the reduction of aqueous solution of $\mathrm{HAuCl}_{4}$ and dilute solution of dendrimers by sodium borohydride [59]. Mathias Ulbricht and co-workers reported the direct and one-step synthesis of water soluble gold nanoparticles of size $<10 \mathrm{~nm}$ with two different thiols including 1-mercaptoundec-11-yl-hexa (ethylene glycol) (EG6) and dodecanethiol (C12) [29].

A non-seed mediated temperature synthesis method of gold nanoparticles has been developed. In this method gold nanoparticles having mean diameter of $75+10 \mathrm{~nm}$ were prepared by the reduction of gold ions in ethylene glycol with $\mathrm{NaOH}$ as reducing agent [30]. Flow micro-reactor system is applied for the synthesis of gold nanoparticles by the reduction of gold (III) chloride complex ion through glucose as reducing agent and poly vinyl pyrrolidone (PVP) as a stabilizing agent [4]. The highly stable gold nanoparticles of size $7.8+1.7 \mathrm{~nm}$ have been synthesized through reduction of $\mathrm{HAuCl}_{4}$ by sodium borohydride as reducing agent. In this method bovine serum albumin was used as capping agent and protein capped gold nanoparticles were reported [6]. In 2013, Kawai and co-workers synthesized organogels which were used as template for the preparation of gold nanoparticles by reduction method [64].

Surfactant assisted method has been used for the synthesis of partially functionalized gold nanoparticles by using a bifuntional ligand hexadecyl trimethyl ammonium bromide (CTAB) as linker between solid substrate and gold nanoparticles [9]. Hot injection technique is reported to synthesized gold nanoparticles by using different surfactants such as oleylamine, 1octadecanethiol, poly (N-vinylpyrrolidone), and $\mathrm{AgNO}_{3}$ in 1,5-pentanediol to stabilize the colloidal solution. In this method gold nanoparticles were synthesized by the chemical reduction of gold salt in organic solvent in the presence of stabilizing agent [31].

Another method for the preparation of gold nanoparticles of size $30 \mathrm{~nm}$ was reported. In this method, a new class of block co-polymers were used as template for the synthesis of stabilized gold nanoparticles [6]. Modified burst method has been used for the synthesis of gold nanoparticles containing PEG of size 4 - 15 nm using a mixture of $\mathrm{HAuCl}_{4}$ methanol and two thiol-PEG ligands (PEG-550, PEG-2000) [7]. Well dispersed gold nanoparticles of size $6 \mathrm{~nm}$ have been synthesized by intra-molecular reduction of sodium gold sulfite $\mathrm{Na}_{3} \mathrm{Au}\left(\mathrm{SO}_{3}\right)_{2}$ [32]. Solutionphase synthesis of gold nanoparticles having size $13 \mathrm{~nm}$ by using cetyltrimethyl ammonium bromide (CTAB) as template or capping agent to avoid agglomeration has been reported. 
Recently, the synthesis of gold nanoparticles of size $2-20 \mathrm{~nm}$ is proposed via the reduction of $\mathrm{HAuCl}_{4}$ with sodium borohydride by using ethanol and isopropanol in the presence of tris(2aminoethyl) amine [33].

\section{Physical methods}

The $y$-irradiation method was proved to be best for the synthesis of gold nanoparticles with controllable size and high purity. The $\mathrm{Y}$-irradiation method is adopted to synthesize gold nanoparticles with size $5-40 \mathrm{~nm}$. In this method natural polysaccharide alginate solution was used as stabilizer [34]. Single step y-irradiation method has been adopted to synthesized gold nanoparticles of size $2-7 \mathrm{~nm}$ by using bovine serum albumin protein as stabilizer [11]. Gold nanoparticles are synthesized via photochemical synthetic approach. In this method, $\mathrm{HAuCl}_{4}$ and aqueous glycine solution was exposed to UVirradiation. Basically amino acid capped gold nanoparticles were used as photochemical initiator which is then further functionalized with glycine [12].

Microwave irradiation method was adopted to synthesize gold nanoparticles by using citric acid as a reducing agent and cetyltrimethyl ammonium bromide (CTAB) as a binding agent [23]. Gold nanoparticles are synthesized by adopting heating or photochemical reduction method. Citrate, tartrate, and malate ligands were used to reduce $\mathrm{HAuCl}_{4}$ [31]. Solvent free photo chemical method is also used for the synthesis of gold nanoparticles supported on hydrotalcite, $\mathrm{V}-\mathrm{Al}_{2} \mathrm{O}_{3}$ and $\mathrm{TiO}_{2}$ with size range of $20-140 \mathrm{~nm}$ directly in solid phase [32]. A new technique of photochemical method has been reported for the preparation of gold-polyethylene glycol core-shell nanoparticles with size 10 - 50 $\mathrm{nm}$ in water by adopting redox and polymerization reactions. In this method gold salt was reduced by radical formation coated with polyethylene glycol diacrylate by UV-process with the help of photo-initiator 2-hydroxy-2methyl-1-phenyl-1-propane [35]. Gold nanoparticles are also synthesized by using seed approach. In this method $10-50 \mathrm{~nm}$ sized gold particles were prepared by Co-60 irradiation by using water soluble chitosan as reducing agent [12]. Porous gold nanoparticles were synthesized from alloys of silver and gold. In this method, first of all micro-emulsion of nanoparticles were prepared by using precursors such as $\mathrm{HAuCl}_{4}$ and $\mathrm{AgNO}_{3}$ and then reduced by $\mathrm{NaBH}_{4}$. After that, de-alloying was done by nitric acid [36]. Gold nanoparticles was prepared by microwave irradiation method in which aqueous extracts of
Cissus quadrangularis (CQE) was used as capping agent or reducing agent [37].

\section{Green methods}

Green chemistry synthesis routes are environment friendly and non-toxic. A facile green biosynthesis method for the preparation of gold nanoparticles of size $25+7 \mathrm{~nm}$ was reported by using natural biomaterial egg shell membrane (ESM). In this method ESM was immersed in aqueous solution of $\mathrm{HAuCl}_{4}$ without using any reductant [23]. Another green synthetic approach was developed to synthesized gold sononanoparticles of size $5-17 \mathrm{~nm}$ by using high-power ultrasounds and sodium dehydrate [19].

Gold nanoparticles were successfully synthesized by adopting sun light irradiation method and were modified with folic acid and capped by 6-mercaptopurine. In this method solar energy was used to reduce the gold salt [16]. A new green chemistry method for the preparation of gold nanoparticles has been reported, in which gold nanoparticles were formed in aqueous $\mathrm{NaCl}$ solution from the bulk gold substrate by natural chitosan without using any external stabilizer and reductant [38]. Gold nanoparticles of size $15-80 \mathrm{~nm}$ are also synthesized via another green synthetic route. In this method $\mathrm{HAuCl}_{4}$ was reduced by using citrus fruits juice extracts [Citrus limon, Citrus reticulate and Citrus sinensis] [39]. Edible mushroom was also used for the synthesis of gold nanoparticles via sunlight exposure [40].

\section{APPLICATIONS OF NANOPARTICLES}

Gold nanoparticles have unique electric and magnetic properties due to their shape and size so they have been received great attention in research areas especially in the field of biological tagging, chemical and biological sensing, optoelectronics, photo thermal therapy, biomedical imaging, DNA labelling [1], microscopy and photoacutisc imaging [3], surface-enhanced Raman spectroscopy, tracking and drug delivery, catalysis [5] and cancer therapy [9] (Table 1).

Gold nanoparticles based sensors can detect various metal ions by working on the principle of colour change due to the aggregation of gold nanoparticles. Such types of sensors have been widely used for the detection of copper, mercury lead and arsenic in water [41].

Noble metals such as gold nanoparticles play key role in the synthesis of biosensors due to 
Table 1: Shapes of gold nanoparticles and their applications

\begin{tabular}{|c|c|c|}
\hline Shape & Size & Application \\
\hline Nano rod & $2-5 \mathrm{~nm}$ & Drug delivery and photothermal therapy [15]. \\
\hline Hollow particle & $25 \mathrm{~nm}$ & Photo-electronics, catalysis and cancer therapy [12] \\
\hline Triangular particle & $3.85-7.13 \mathrm{~nm}$ & Highly effective against $E$. coli and $K$. pneumonia [23] \\
\hline Faceted particle & $50-100 \mathrm{~nm}$ & $\begin{array}{l}\text { Effective, reproducible, and stable large area substrates for NIR } \\
\text { SERS [near infra-red surface enhanced Raman spectroscopy] [25] }\end{array}$ \\
\hline Nanocube & $50 \mathrm{~nm}$ & Field enhancement applications and refractive-index sensing [28] \\
\hline Nanocage & $50 \mathrm{~nm}$ & $\begin{array}{l}\text { Effective molecular contrast agent for nonlinear endomicroscopy } \\
\text { imaging [19] and in vivo medical applications [29] }\end{array}$ \\
\hline Nanobelt & $\begin{array}{l}\text { Thickness, } \sim 80 \\
\mathrm{~nm} \text {, Width, } \sim 20 \\
\mu \mathrm{m} \text {, Length, } \\
\sim 0.15 \mathrm{~m} .\end{array}$ & Strain sensors \\
\hline Branched particle & $90 \mathrm{~nm}$ & Substrates for SERS-based imaging of kidney cells [30] \\
\hline
\end{tabular}

large surface area, small size, good biocompatibility, conductivity, and excellent catalytic properties. Nanoparticles combined with biomolecules have been used for the biosensing applications such as combination of gold nanoparticles and AuNPs/MPA (mercaptopropionic acid) has been used in the fabrication of biosensors which shows wide linear range between $0.25 \mathrm{mM}$ and $1.25 \mathrm{mM}$ glucose concentration having detection limit of $0.025 \mathrm{mM}$ [42] (Figure 4). Most of the biosensors depend on LSPR (localized surface plasmon resonance) of gold nanoparticles so in order to enhance the efficiency of biosensors gold nanoparticles have been immobilized in solid substrate [10]. Functionalized gold nanoparticles with calixarene derivatives, crown ethers DNA and peptides [12] have been used for the sensing applications mainly for the recognition of amino acids, quaternary ammonium ions and pyridinium [13]. Indium tin oxide electrode modified with gold nanoparticles/ $/ \mathrm{TiO}_{2}$ composites has been used for the estimation of catechol (CC) and hydroquinone (HQ) with the help of voltametric method. Catechol has been successfully determined in tea sample by adopting this method [35]. Another important application of gold nanoparticles is in memory devices. Gold nanoparticles coated with suitable insulator exhibit excellent stability for memory devices and this insulation helps in prevention of accumulation of charges when the applied field has been removed [43].

\section{COMMON DRUGS FOR CANCER THERAPY}

Constructive pathways for clinical treatment of cancer are confined. Surgical restriction, chemotherapy and irradiation are some common tactics used for cancer therapy but these approaches are not only toxic, non-specific but also cause various side effects [11]. Cancer patients undergoing radio and chemotherapy face drug resistance such as cisplatin, cancer related fatigue (CRF) and several cardio vascular effects such as cardiomyopathy, ischemia, arrhythmias, hyper tension, thromboembolism, pericardial diseases or heart attack as they damage the cancer cells along with the destruction of healthy cells [44].

Besides of some conventional approaches, chemotherapy remains the primary treatment for cancer but it is not much restorative because of various side effects caused by unspecified drug distribution in the body due to several chemotherapeutic agents such as cytotoxic drugs [25]. Paclitaxel (PTX) shows cytotoxicity against different types of cancer so it is considered to be an essential chemotherapeutic drug with limited therapeutic effects due to toxicity caused by poor water solubility and selectivity. Because of these shortcomings, effective approaches should be considered [28]. Chemotherapeutic agents cause various side effects in cancer patients such as nephrotoxicity, vomiting, myelosuppression, severe nausea, ototoxicity and neurotoxicity due to CDDP (cisplatin) administration whereas gastro intestinal disturbances, acute nausea, vomiting, stomatitis, alopecia baldness, neurologic disturbances, bone marrow, aplasia, cumulative cardio toxicity and bone marrow depressant effects due to doxorubicin administration [9].

Due to fluoropyrimidines (5FU), methotrexate, irinotecan and cisplatin patient may suffer from adverse diarrhea and constipation [30]. When treated with temsirolimus as a single drug anemia, hyperglycemia, stomatitis, hypophosphatemia, interstitial lung disease and pneumonia were reported in patients suffering from advanced renal cell carcinoma [31]. Each 
Table 2: Conventional intravenously administered drugs and their side effects

\begin{tabular}{|c|c|c|}
\hline $\begin{array}{l}\text { Chemotherapeutic } \\
\text { agent }\end{array}$ & Cancer type & Possible short-term side effect \\
\hline $\begin{array}{l}\text { Carboplatin } \\
\text { (Paraplatin) }\end{array}$ & $\begin{array}{l}\text { Cancers of the ovary, head } \\
\text { and neck, and lungs }\end{array}$ & $\begin{array}{l}\text { Decrease in blood cell counts, hair loss (reversible), } \\
\text { confusion, nausea, vomiting, and/ordiarrhea }\end{array}$ \\
\hline $\begin{array}{l}\text { Cisplatin (Platinol, } \\
\text { Platinol-AQ) }\end{array}$ & $\begin{array}{l}\text { Cancers of the bladder, } \\
\text { ovary, and testicles }\end{array}$ & $\begin{array}{l}\text { Decrease in blood cell counts, allergic reaction, including } \\
\text { a rash and/or labored breathing, nausea and vomiting that } \\
\text { usually occurs for } 24 \text { hours or longer, ringing in ears and } \\
\text { hearing loss, fluctuations in blood electrolytes, and kidney } \\
\text { damage }\end{array}$ \\
\hline $\begin{array}{l}\text { Doxorubicin } \\
\text { (Adriamycin) }\end{array}$ & $\begin{array}{l}\text { Breast cancer, lymphoma, } \\
\text { and multiplemyeloma }\end{array}$ & $\begin{array}{l}\text { Decrease in blood cell counts, mouth ulcers, hair loss } \\
\text { (reversible), nausea and vomiting, and heart damage }\end{array}$ \\
\hline Paclitaxel (Taxol) & $\begin{array}{l}\text { Cancers of the breast, } \\
\text { ovary, and lung }\end{array}$ & $\begin{array}{l}\text { Decrease in blood cell counts, allergic reaction, nausea } \\
\text { and vomiting, loss of appetite, change in taste, thin or } \\
\text { brittle hair, joint pain (short term), and numbness or } \\
\text { tingling in fingers or toes }\end{array}$ \\
\hline Fluorouracil (5-FU) & $\begin{array}{l}\text { Cancers of the colon, } \\
\text { breast, stomach, and head } \\
\text { and neck }\end{array}$ & $\begin{array}{l}\text { Decrease in blood cell counts, diarrhea, mouth ulcers, } \\
\text { photosensitivity, and dry skin }\end{array}$ \\
\hline
\end{tabular}

year, large numbers of deaths are caused by cancer because lack of selectivity, drug targeting ability, inefficient metastatic tumor therapy and drug resistant tumor cells (Table 2). Therefore advanced chemotherapic treatments have been needed to kill cancerous cells [32]. Today in order to avoid side effects fuscous of scientists are shifted towards natural products which still needs to prove their effectiveness [45].

\section{GOLD NANOPARTICLE-MEDIATED DRUG DELIVERY}

Targeted drug delivery is better than conventional drug therapy because in targeted drug delivery drugs target the main effected area and delivered drug locally so it minimize the side effects caused by conventional drugs [34]. Primary goal of developing anticancer agents is to minimize the various side effects caused by the conventional drugs and to improve selectivity and efficiency of drug [35]. Targeted drug delivery is the main area of interest for scientists recently and a lot of work has been done to synthesized systems for targeted drug delivery such as nanoparticles, quantum dots, polymer gels, $\mathrm{Fe}_{3} \mathrm{O}_{4}$, and $\mathrm{ZnO}$ [18].

Gold nanoparticles have the ability of bio-imaging of the effected cancerous cells for therapy [13]. For effective drug delivery system or drug therapy it is important to investigate about the biological effects of the nanoparticles [17] as gold nanoparticles have unique physical and chemical properties and have strong binding attraction for thiols, proteins [18], carboxylic acid [11] aptamers [39] and disulfides so they have been extensively used in the field of biosciences especially in drug delivery for cancer therapy. Gold nanoparticles followed three main pathways for the cellular uptake which includes receptormediated endocytosis, phagocytosis and fluidphase endocytosis [40].

The toxicity of gold nanoparticles depends on the size, shape, synthesis method, surface charge, surface coating and functionalized molecules but overall cytotoxicity of gold nanoparticles is in acceptable level as gold nanoparticles are considered to be non-toxic agents [44]. There are two factors, i.e. drug release and transport, which are very important for the efficient drug delivery system. Drugs are loaded on nanocarriers by noncovalent interaction or through covalent conjugation with the help of pro-drug, which is treated by the cell. Gold nanoparticles have functional flexibility due to their monolayers so they provide efficient system [45].

\section{ADVANTAGES OF GOLD NANOPARTICLES}

Gold nanoparticles mediated drug delivery systems have many advantages over other nanocarriers as well as to conventional drugs. Gold nanoparticles have been widely used as acancer antigen and in tumor therapies [15]. Some advantages are listed here; (i) Gold nanoparticles have unique optical [16], physical and chemical properties [7] due to their size and shape [9]; (ii) Gold nanoparticles have high surface area [17] which provide dense drug loading; (iii) These particles are biocompatible [1] and are readily available for conjugation with small biomolecules such as proteins, enzymes, carboxylic acid, DNA, and amino acids [2]; (iv) 
Gold nanoparticles have controlled dispersity [5]; (v) Due to small size and uniform dispersion they can easily reach to the targeted site with blood flow [36]; (vi) They are non-cytotoxic to the normal cells [18]; and (vii) Gold nanoparticles are easily synthesized by various methods [22].

\section{CONCLUSION}

Gold nanoparticles have, in some ways, revolutionized the field of medicine because of its wide spread applications in targeted drug delivery, imaging, diagnosis and therapeutics due to their extremely small size, high surface area, stability, non-cytotoxicity and tunable optical, physical and chemical properties. Functionalized gold nanoparticles with various biomolecules such as proteins, DNA, amino acids and carboxylic acids have been used in cancer therapy and provide excellent drug delivery system. Targeted delivery and programmed release of therapeutic drugs to the specific site is achieved by using gold nanoparticles because they can bear high drug load and release it to the specific site through various administration routes and can interact with cancerous cell. Side effects of conventional drugs have been minimized by conjugation with gold nanoparticles and they increase the quality life of patients.

\section{REFERENCES}

1. F.K. Alanazi, A.A. Radwan, and I.A. Alsarra. Biopharmaceutical applications of nanogold. Saudi Pharm J 2010; 18: 179-193.

2. Di Guglielmo C, Lopez DR, De Lapuente J, Mallafre JM, Suarez MB. Embryotoxicity of cobalt ferrite and gold nanoparticles: a first in vitro approach. Reproduct Toxicol 2010; 30: 271-276.

3. Kim D, Jon S. Gold nanoparticles in image-guided cancer therapy. Inorgan Chim Acta 2012; 393: 154-164.

4. Khlebtsov NG, Dykman LA. Optical properties and biomedical applications of plasmonic nanoparticles. $J$ Quantitat Spectroscop Radiat Transf 2010; 111: 1-35.

5. Tedesco S, Doyle H, Blasco J, Redmond G, Sheehan D. Oxidative stress and toxicity of gold nanoparticles in Mytilus edulis. Aquatic Toxicol 2010; 100: 178-186.

6. Mendoza KC, McLane VD, Kim S, Griffin JD. Invitro application of gold nanoprobes in live neurons for phenotypical classification, connectivity assessment, and electrophysiological recording. Brain Res 2010; 1325: 19-27.

7. Hartono D, Hody, Yang KL, Yung LY. The effect of cholesterol on protein-coated gold nanoparticle binding to liquid crystal-supported models of cell membranes. Biomater 2010; 31: 3008-3015.
8. Lukianova-Hleb EY, Wagner DS, Brenner MK, Lapotko DO. Cell-specific transmembrane injection of molecular cargo with gold nanoparticle-generated transient plasmonic nanobubbles. Biomater 2012; 33: 5441-5450.

9. Mishra A, Tripathy SK, Yun S-I. Fungus mediated synthesis of gold nanoparticles and their conjugation with genomic DNA isolated from Escherichia coli and Staphylococcus aureus. Process Biochem 2012; 47: 701-711.

10. Etame AB, Smith CA, Chan WC, Rutka JT. Design and potential application of PEGylated gold nanoparticles with size-dependent permeation through brain microvasculature. Nanomed: Nanotechnol Biol Med 2011; 7: 992-1000.

11. Deb S, Patra HK, Lahiri P, Dasgupta AK, Chakrabarti K, Chaudhuri U. Multistability in platelets and their response to gold nanoparticles. Nanomed: Nanotechnol Biol Med 2011; 7: 376-384.

12. Ganeshkumar M, Sastry TP, Sathish Kumar M, Dinesh MG, Kannappan S, Suguna L. Sun light mediated synthesis of gold nanoparticles as carrier for 6mercaptopurine: Preparation, characterization and toxicity studies in zebrafish embryo model. Mater Res Bull 2012; 47: 2113-2119.

13. Pal R, Panigrahi S, Bhattacharyya D, Chakraborti AS. Characterization of citrate capped gold nanoparticlequercetin complex: Experimental and quantum chemical approach. J Mol Struct 2013; 1046: 153163.

14. Stobiecka M, Hepel M. Double-shell gold nanoparticlebased DNA-carriers with poly-L-lysine binding surface. Biomater 2011; 32: 3312-3321.

15. Guo Q, Guo Q, Yuan J, Zeng J. Biosynthesis of gold nanoparticles using a kind of flavonol: Dihydromyricetin. Colloids and Surfaces A: Physicochemical and Engineering Aspects 2014; 441: 127-132.

16. Lan M-Y, Hsu Y-B, Hsu C-H, Ho C-Y, Lin J-C, Lee S-W. Induction of apoptosis by high-dose gold nanoparticles in nasopharyngeal carcinoma cells. Auris Nasus Larynx 2013; 40: 563-568.

17. Chithrani $D B$, Dunne $M$, Stewart J, Allen C, Jaffray $D A$. Cellular uptake and transport of gold nanoparticles incorporated in a liposomal carrier. Nanomed: Nanotechnol Biol Med 2010; 6: 161-169.

18. Lee $K$, Lee $H$, Bae KH, Park TG. Heparin immobilized gold nanoparticles for targeted detection and apoptotic death of metastatic cancer cells. Biomater 2010; 31: 6530-6536.

19. Giljohann DA, Seferos DS, Daniel WL, Massich MD, Patel PC, Mirkin CA. Gold nanoparticles for biology and medicine. Angewandte Chem 2010; 49: 32803294.

20. Amjadi M, Farzampour L. Fluorescence quenching of fluoroquinolones by gold nanoparticles with different sizes and its analytical application. J Luminesc 2014; 145: 263-268.

Trop J Pharm Res, July 2014; 13(7):1176 
21. Gou XC, Liu J, Zhang HL. Monitoring human telomere DNA hybridization and G-quadruplex formation using gold nanorods. Anal chim acta 2010; 668: 208-214.

22. Gao W, Xu K, Ji L, Tang B. Effect of gold nanoparticles on glutathione depletion-induced hydrogen peroxide generation and apoptosis in HL7702 cells. Toxicol Lett 2011; 205: 86-95.

23. Murawala $P$, Tirmale $A$, Shiras A, Prasad BLV. In situ synthesized BSA capped gold nanoparticles: Effective carrier of anticancer drug Methotrexate to MCF-7 breast cancer cells. Mater Sci Engineer C 2014; 34: 158-167.

24. Ghosh R, Singh LC, Shohet JM, Gunaratne PH. A gold nanoparticle platform for the delivery of functional microRNAs into cancer cells. Biomater 2013; 34: 807816.

25. Papasani MR, Wang G, Hill RA. Gold nanoparticles: the importance of physiological principles to devise strategies for targeted drug delivery. Nanomed: Nanotechnol Biol Med 2012; 8: 804-814.

26. Sun $X$, Zhang $G$, Keynton RS, O'Toole MG, Patel $D$, Gobin AM. Enhanced drug delivery via hyperthermal membrane disruption using targeted gold nanoparticles with PEGylated Protein-G as a cofactor. Nanomed: Nanotechnol Biol Med 2013; 9: 1214-1222.

27. Heidari Z, Sariri R, Salouti M. Gold nanorods-bombesin conjugate as a potential targeted imaging agent for detection of breast cancer. J Photochem Photobiol B: Biol 2014; 130: 40-46.

28. Pissuwan D, Niidome T, Cortie MB. The forthcoming applications of gold nanoparticles in drug and gene delivery systems. J Control Release 2011; 149: 6571.

29. Bisker G, Yeheskely-Hayon D, Minai L, Yelin D. Controlled release of Rituximab from gold nanoparticles for phototherapy of malignant cells. J Control Release 2012; 162: 303-309.

30. Paino IM, Marangoni VS, de Oliveira Rde C, Antunes LM, Zucolotto V. Cyto and genotoxicity of gold nanoparticles in human hepatocellular carcinoma and peripheral blood mononuclear cells. Toxicology letters 2012; 215: 119-125.

31. Guo W, Pi Y, Song H, Tang W, Sun J. Layer-by-layer assembled gold nanoparticles modified anode and its application in microbial fuel cells. Colloid Surfac A: Physicochem Engineer Aspects 2012; 415: 105-111.

32. Sawada H, Takahashi K. Facile preparation of gold nanoparticles through autoreduction of gold ions in the presence of fluoroalkyl end-capped cooligomeric aggregates: LCST-triggered sol-gel switching behavior of novel thermoresponsive fluoroalkyl endcapped cooligomeric nanocomposite-encapsulated gold nanoparticles. J Colloid Interfac Sci 2010; 351: 166-170.

33. Khan MS, Vishakante GD, Siddaramaiah $H$. Gold nanoparticles: A paradigm shift in biomedical applications. Advanc Colloid Interfac Sci 2013; 199200: 44-58.

34. Rezende TS, Andrade GRS, Barreto LS, Costa Jr NB, Gimenez IF, Almeida LE. Facile preparation of catalytically active gold nanoparticles on a thiolated chitosan. Mater Lett 2010; 64: 882-884.

35. Chen K-S, Hung T-S, Wu H-M, Wu J-Y, Lin M-T, Feng CK. Preparation of thermosensitive gold nanoparticles by plasma pretreatment and UV grafted polymerization. Thin Solid Films 2010; 518: 75577562.

36. Kojima C, Umeda Y, Harada A, Kono K. Preparation of near-infrared light absorbing gold nanoparticles using polyethylene glycol-attached dendrimers. Colloid Surfac B, Biointerfac 2010; 81: 648-651.

37. Pérez $Y$, Mann E, Herradón B. Preparation and characterization of gold nanoparticles capped by peptide-biphenyl hybrids. J Colloid Interfac Sci 2011; 359: 443-453.

38. Namazi H, Fard AMP. Preparation of gold nanoparticles in the presence of citric acid-based dendrimers containing periphery hydroxyl groups. Mater Chem Physic 2011; 129: 189-194.

39. Tarnawski R, Ulbricht M. Amphiphilic gold nanoparticles: Synthesis, characterization and adsorption to PEGylated polymer surfaces. Colloid Surfac A: Physicochem Engineer Aspects 2011; 374: 13-21.

40. Nalawade $P$, Mukherjee $T$, Kapoor S. High-yield synthesis of multispiked gold nanoparticles: Characterization and catalytic reactions. Colloid Surfac A: Physicochem Engineer Aspects 2012; 396: 336-340.

41. Pacławski K, Streszewski B, Jaworski W, Luty-Błocho $M$, Fitzner $K$. Gold nanoparticles formation via gold(III) chloride complex ions reduction with glucose in the batch and in the flow microreactor systems. Colloid Surfac A: Physicochem Engineer Aspects 2012; 413: 208-215.

42. Rastogi L, Kora AJ, J A. Highly stable, protein capped gold nanoparticles as effective drug delivery vehicles for amino-glycosidic antibiotics. Mater Sci Engineer: C 2012; 32: 1571-1577.

43. Delbecq F, Tsujimoto K, Ogue $Y$, Endo H, Kawai T. Nstearoyl amino acid derivatives: potent biomimetic hydro/organogelators as templates for preparation of gold nanoparticles. J Colloid Interfac Sci 2013; 390: 17-24.

44. Benkovicova M, Vegso K, Siffalovic P, Jergel M, Luby S, Majkova E. Preparation of gold nanoparticles for plasmonic applications. Thin Solid Films 2013; 543: 138-141.

45. Yu L, Qiu J-J, Cheng H, Luo Z-H. Facile preparation of gold nanoparticles using the self-assembled $A B C$ non-amphiphilic fluorosilicone triblock copolymer template. Mater Chem Physic 2013; 138: 780-786.. 